\title{
Molecular identification of Bartonella bacilliformis in ticks collected from two species of wild mammals in Madre de Dios: Peru
}

\author{
Juana del Valle-Mendoza ${ }^{1,2^{*}}{ }^{+}$, Jesús Rojas-Jaimes ${ }^{3 \dagger}$, Fernando Vásquez-Achayaa ${ }^{1}$, Miguel Angel Aguilar-Luis ${ }^{1,2,4}$, \\ Germán Correa-Nuñez ${ }^{5}$, Wilmer Silva-Caso ${ }^{1}$, Andrés G. Lescano ${ }^{6}$, Xiuping Song ${ }^{7}$, Qiyong Liu ${ }^{7}$ and Dongmei Li ${ }^{7 *}$
}

\begin{abstract}
Objective: To study the presence of Bartonella bacilliformis in ticks collected from two wild mammals in Madre de Dios, Peru.

Results: A total of 110 ticks were collected. Among the 43 Amblyomma spp. extracted from the 3 Tapirus terrestris only 3 were positive for B. bacilliformis. In addition, 12 out of the 67 Rhipicephalus (Boophilus) microplus obtained from the 3 Pecari tajacu were positive for B. bacilliformis. For the first time B. bacilliformis have been detected in arthropods other than Lutzomyia spp. Further studies are required to elucidate the possible role of ticks in the spread of South American Bartonellosis.
\end{abstract}

Keywords: Bartonella bacilliformis, Carrion's disease, Ticks, Peru, PCR

\section{Introduction}

Bartonella species are fastidious, gram-negative bacteria associated with a wide spectrum of disease manifestations in humans and animals [1-3]. Bartonella spp. are organisms transmitted by a variety of bloodsucking arthropod vectors including fleas, ticks, sandflies and other insects capable of infecting humans [3, 4]. The bacteria are known to invade and replicate inside mammalian hosts erythrocytes and endothelial cells causing long-lasting bacteremia $[5,6]$.

South American Bartonellosis or Carrion's disease is an infection caused by Bartonella bacilliformis which was

\footnotetext{
*Correspondence: juana.delvalle@upc.pe; joana.del.valle@gmail.com; lidongmei@icdc.cn

†Juana del Valle-Mendoza and Jesús Rojas-Jaimes contributed equally to this work

${ }^{1}$ School of Medicine, Research and Innovation Centre of the Faculty of Health Sciences, Universidad Peruana de Ciencias Aplicadas, Lima, Peru 7 State Key Laboratory for Infectious Disease Prevention and Control, Collaborative Innovation Center for Diagnosis and Treatment of Infectious Diseases, National Institute for Communicable Disease Control and Prevention, Chinese Center for Disease Control and Prevention (China CDC), P.O. Box5, Changping District, Beijing 102206, People's Republic of China

Full list of author information is available at the end of the article
}

first described in Peru in 1885 [1]. The infection causes an initially life-threatening phase, known as "Oroya fever", and the second phase with chronic cutaneous manifestations called "Verruga Peruana" [3, 7]. Oroya fever is characterized by acute fever and hemolytic anemia with case fatality rates up to $88 \%$ in untreated patients. In contrast, the verruga peruana presents as angiogenic benign skin lesions which are self-limiting and can persist for 6 months [7-9]. However, most patients with Verruga Peruana do not have a clear previous history of febrile illness $[7,10]$.

Bartonella bacilliformis is known to be transmitted by the bite of the female sandfly from the genus Lutzomyia spp. and humans are considered the only reservoir host $[3,9]$. Due to the favorable ecological conditions for the Lutzomyia spp., the disease has been historically restricted to remote valleys located between 500 and $3200 \mathrm{~m}$ (1600-10,500 feet) above sea level in the Andes Mountains of Peru, Colombia, and Ecuador [7, 9, 11]. However, in the last years, the disease has been expanding over broader geographical areas including lower altitude territories, high forest regions and valleys located in the eastern regions of the Andes representing a major 
health problem to populations living in endemic areas and travelers visiting these territories $[12,13]$.

Peru is the only endemic country with Carrion's disease reported in 11 of its 24 departments. In addition, the disease resurgence in areas of extreme poverty has become an challenge to the country in terms of vector control and disease burden reduction $[11,14,15]$. Lutzomyia verrucarum is the most effective vector in Peru, with occasional outbreaks in nonendemic areas in which other species of Lutzomyias have been described, such as L. maranonensis, L. robusta, and L. Peruensis suggesting Lutzomyias species adaptation to different climates and heights [16-18]. However, a possible the spreading of $L$. verrucarum and other species to new areas is not sufficiently studied in Peru and a comprehensive surveillance is needed to rule out potential secondary vectors in South American regions, which may account for Carrion's disease dissemination [19].

As new Bartonella spp. are discovered, the list of reservoir-adapted species and potential vectors for transmission is growing at a fast pace [20]. Furthermore, ticks have been extensively described as vectors for $B$. birtlesii, $B$. henselae, B. grahamii, B. chomelii, among other species of Bartonella, but not for B. bacilliformis yet [4, 2123]. The aim of the present investigation is to study tick species as potential vectors for B. bacilliformis transmission via real-time PCR detection in ticks collected from two areas located in Madre de Dios, Peru.

\section{Main text \\ Methods \\ Study area}

The study was conducted in two areas located in the department of Madre de Dios, Peru. Both regions are in the Tahuamanu River basin, near Bolivia border territories. The collection sites are located in a forest area where wildlife hunting activity occurs. The climate is humid and warm, with average annual precipitation of $1600 \mathrm{~mm}$ and an average annual temperature of $25^{\circ} \mathrm{C}$.

\section{Sample collection and tick species identification}

The 3 Tapirs (Tapirus terrestris) from San Lorenzo city and the 3 Collared peccaries (Pecari tajacu) from Botijon town were captured for tick extraction with tweezers and then they were released with no harm. A total of 110 ticks were collected and stored individually in ethyl alcohol (96\%) for preservation until they were transported to the Entomology Laboratory of the National Institute of Health "INS-Lima-Peru" for identification following the protocol published by Barros-Battesti [24]. All ticks were successfully identified and classified (Table 1).

This study was approved by the National Committee of Health and Environment from the Regional Government of Madre de Dios.

\section{DNA extraction}

The ticks were processed individually, each individual was cut into pieces with the help of a scalpel and homogenized in $180 \mu \mathrm{L}$ of PBS $1 \mathrm{X}$ and then the extraction of the genetic material was carried out. The DNA was extracted using the DNeasy ${ }^{\circledR}$ Blood and Tissue Kit (Qiagen), according to the manufacturer's instructions except that the final elution volume was $200 \mu \mathrm{L}$. The samples were stored at $4{ }^{\circ} \mathrm{C}$ until use, being thereafter stored at $-20^{\circ} \mathrm{C}$.

Real-time PCR assay detection of Bartonella bacilliformis

The qPCR was performed based on Li et al. protocol [25]. Each reaction contained $5 \mu \mathrm{L}$ of template DNA and $15 \mu \mathrm{L}$

Table 1 Ticks collected from San Lorenzo city and Botijon Town in Madre de Dios, Peru

\begin{tabular}{lcll}
\hline Region/animal & Number of ticks $\mathbf{( n = 1 1 0 )}$ & Lifecycle stages & Species \\
\hline San Lorenzo city/Tapirus terrestris & 14 & Adult male & Amblyomma scalpturatum \\
& 6 & Adult female & Amblyomma scalpturatum \\
& 9 & Adult male & Amblyomma naponense \\
& 5 & Adult female & Amblyomma naponense \\
Botijon Town/Collared peccary & 1 & Adult female & Amblyomma latepunctatum \\
& 3 & Adult male & Amblyomma latepunctatum \\
& 1 & Adult female & Amblyomma oblongoguttatum \\
& 1 & Adult male & Amblyomma ovale \\
& 22 & Adult female & Amblyomma ovale \\
& 41 & Adult female & Rhipicephalus (Boophilus) microplus \\
& 4 & Adult male & Rhipicephalus (Boophilus) microplus \\
& & Nymphs & Rhipicephalus (Boophilus) microplus
\end{tabular}


of the qPCR master mix (FastStar PCR Master, Roche Diagnostic, Alemania) including $1(10 \mu \mathrm{M})$ each of forward and reverse primers and $1.2(10 \mu \mathrm{M})$ Taqman probe. Briefly, qPCR conditions were $95^{\circ} \mathrm{C}$ for $2 \mathrm{~min}, 55$ cycles of $3 \mathrm{~s}$ at $95^{\circ} \mathrm{C}, 30 \mathrm{~s}$ at $55^{\circ} \mathrm{C}$ and $10 \mathrm{~s}$ at $72{ }^{\circ} \mathrm{C}$. The B. bacilliformis collection strain (CIP 57.19, NCTC 12135) was used as the positive control, while PCR reaction without template DNA was used as the negative control.

\section{Results}

A total of 110 ticks were collected from both study regions. In San Lorenzo city, 43 ticks were collected from 3 Tapirus Terrestris; the most common species were Amblyomma scalpturatum, Amblyomma naponense, Amblyomma latepunctatum and Amblyomma oblongoguttatum. In Botijon town, 67 ticks were collected from 3 collared peccaries and all were identified as Rhipicephalus (Boophilus) microplus (Table 1).

All tick species were tested for the presence of $\mathrm{B}$. bacilliformis via real-time PCR. Among the ticks collected from the Tapirus terrestris, only 3 were positive for $B$. bacilliformis: 2 adult Amblyomma scalpturatum (male and female) and 1 Adult female Amblyomma ovale. Among the Rhipicephalus (Boophilus) microplus extracted from the collared peccaries, 12 were positive for B. bacilliformis (4 adult females, 7 adult males, and 1 nymph) (Table 2).

\section{Discussion}

Bartonella species are emerging zoonotic organisms capable of producing long-lasting infections transmitted by arthropods. Bartonella bacilliformis is the most frequent species of Bartonella in Peru and the responsible for Carrion's disease a neglected tropical infection endemic in this country $[3,9]$.

South American Bartonellosis is an ancient illness, probably existing at least 1000 years before the arrival of Europeans since there is evidence of pre-Columbian pottery from Ecuador representing cutaneous manifestations of the disease [26]. In 1885, a Peruvian medical student named Daniel Alcides Carrion self-inoculated $B$. bacilliformis demonstrating that the two phases of illness are caused by the same bacteria and as a recognition to his sacrifice, the infection is also known as Carrion's disease [27]. But it wasn't until 1913 when the female sandfly Lutzomyia verrucarum was confirmed as the vector responsible for its transmission to humans [11, 28].

Since the late 1990s, reports have confirmed a slow but steady increase of Carrion's disease cases; this resurgence could be explained due to several factors including the new diagnostic tests available and climate changes which in addition to the human activities such as agriculture or hydroelectric installations may have contributed to the vector expansion to new areas [19]. Moreover, the El Niño phenomenon has created increased rainfall across the east-central and Eastern Pacific Ocean raising humidity levels favoring the sand fly's reproduction and vector expansion $[28,29]$. However, the insidious extension of the South American Bartonellosis in areas where the Lutzomyia genus is absent suggest the presence of undescribed vectors for B. bacilliformis [28].

Since 2004, the National Institute of Health has reported Carrion's disease outbreaks in Madre de Dios and to date, the $L$. verrucarum is recognized as the principal vector, with other species of Lutzomyia such as $L$. auraensis, also present in the region, although these species are not vectors for the disease [30-32]. More importantly, B. bacilliformis infections have also been reported in territories such as San Lorenzo city and Botijon Town despite being located at 267 and 285 m.a.s.l, a much lower altitude than the 500 m.a.s.l where Lutzomyia spp. are commonly found. Moreover, tick-borne diseases are a significant problem in Madre de Dios and tick species, which are commonly found in Tapirus terrestris and Tayassu pecari across the territory, represent a potential vector for tropical infections [33].

In our study, we detected $B$. bacilliformis via realtime PCR in 3 Amblyomma spp. (Amblyomma scalpturatum and Amblyomma ovale) ticks from Tapirus terrestris and in 12 Rhipicephalus (Boophilus) microplus extracted from the collared peccaries. This is the first-time $B$. bacilliformis have been detected in an

Table 2 Ticks positives for Bartonella bacilliformis via Real time PCR

\begin{tabular}{llll}
\hline Region/animal & $\begin{array}{l}\text { Number of ticks positive for } \boldsymbol{B} . \\
\text { bacilliformis }(\mathbf{n}=\mathbf{1 5})\end{array}$ & Lifecycle stages & Species \\
\hline San Lorenzo city/Tapirus terrestris & 1 & Adult male & Amblyomma scalpturatum \\
& 1 & Adult female & Amblyomma scalpturatum \\
Botijon Town/Collared peccary & 1 & Adult female & Amblyomma ovale \\
& 4 & Adult female & Rhipicephalus (Boophilus) microplus \\
& 7 & Adult male & Rhipicephalus (Boophilus) microplus \\
& 1 & Nymphs & Rhipicephalus (Boophilus) microplus \\
\hline
\end{tabular}


arthropod other than Lutzomyia spp. sand flies and could suggest that some tick species may be vectors for B. bacilliformis.

Polymerase chain reaction for Bartonella spp. isolation in arthropods is one the best available options to investigative potential vectors for these bacteria [21,34]. However, the role of ticks in B. bacilliformis transmission is unknown; in contrast to other species of Bartonella which have been previously described as transmitted by ticks [4, 21-23].

In 2016, a genomic analysis on seven genera of bacteria (Borrelia, Rickettsia, Anaplasma, Bartonella, Ehrlichia, Francisella and Coxiella) described multiple pathways to mutualism for tick-borne pathogens which may confer ticks the ability to transmit new species of bacteria [35]. Unfortunately, the exact mechanisms that allow Bartonella to be arthropod-borne are unknown. However, it has been postulated that the ability of pathogens to be tick-transmitted may involve accumulated mutations in various genes during their evolution. Moreover, there are multiple metabolic pathways common to tick and other arthropods that may explain how bacteria adapt to new vectors, but most of them remain under investigation $[36,37]$.

Although the rate of evolution is greater in pathogens that are transmitted by specialized vectors, it is the rate of gene loss the phenomenon that occurs more frequently and Bartonella spp. are no exception. For example, $B$. henselae, a flea-borne pathogen, has a genome reduction of $12.6 \%$ in comparison to B. quintana, proving that this bacterium is a genomic derivate from $B$. henselae that adapted to be transmitted by louse [37]. Therefore, it is possible that other species of Bartonella such as B. bacilliformis might adapt to newer vectors such as ticks, but currently, there is no evidence available.

Humans are the only recognized reservoir for South American Bartonellosis and they play a significant role as perpetrators of the disease in areas of high endemicity [11]. Several reservoir candidates have been postulated for B. bacilliformis, from Euphorbiaceae to domestic and wild rodents; however, no study has been able to isolate the bacteria from these animals [38].

A possible explanation for Bartonella spp. transmission between mammals can be related to Lutzomyia species behavior as opportunistic feeders. A study conducted in an area endemic to cutaneous leishmaniasis in Lima, Peru reported that after humans the most frequent bloodmeals for Lutzomyia peruensis and L. verrucarum were cows and cats. Even though both Lutzomyias are recognized vectors for Carrion's disease, studies are far to prove that $B$. bacilliformis can be transmitted to other mammals [39].
In conclusion, even though there are not studied mechanisms of adaptation to new vectors for $B$. bacilliformis, our results are the first ones to highlight the presence of this bacteria's DNA in tick species. Novel studies are required to elucidate whether $B$. bacilliformis to be transmitted by ticks and the possible role of ticks in the spread of South American Bartonellosis.

\section{Limitations}

For the first time, we have been able to isolate $B$. bacilliformis DNA in ticks from Tapirus terrestris and Pecari tajacu. However, we cannot conclude that both animals were infected or they served as a reservoir. An important limitation of this study was our inability to extract serum from these mammals for $B$. bacilliformis detection since blood collection required trained veterinary personnel.

\section{Abbreviations}

PCR: polymerase chain reaction; DNA: deoxibonucleic acid; bp: base pairs; $B$. bacilliformis: Bartonella bacilliformis; PBS: phosphate buffered saline.

\section{Authors' contributions}

JdVM, DL and JRJ designed the study protocol. JdVM, DL, FVA, WSC, and MAAL performed the PCR for pathogens. JdVM, MAAL, JRJ, GCN, WGL, XS and $Q L$ was responsible for the clinical assessment, samples collection, database adquisition, analysis and interpretation data. JdVM, WS, DL, XS, and QL drafted the manuscript. All authors critically revised the manuscript for intellectual content. All authors read and approved the final manuscript.

\section{Author details \\ ${ }^{1}$ School of Medicine, Research and Innovation Centre of the Faculty of Health Sciences, Universidad Peruana de Ciencias Aplicadas, Lima, Peru. ${ }^{2}$ Laboratorio de Biología Molecular, Instituto de Investigación Nutricional, Lima, Peru. ${ }^{3}$ Lab- oratorio de Biología Molecular y Celular, Escuela de Medicina Humana, Univer- sidad Científica del Sur, Lima, Peru. ${ }^{4}$ Instituto de Investigación de Enferme- dades Infecciosas, Lima, Peru. ${ }^{5}$ Departamento Académico de Ciencias Básicas, Universidad Nacional Amazónica de Madre de Dios, Puerto Maldonado, Peru. \\ ${ }^{6}$ Emerge, Emerging Diseases and Climate Change Research Unit, School of Public Health and Administration, Universidad Peruana Cayetano Heredia, Lima, Peru. ${ }^{7}$ State Key Laboratory for Infectious Disease Prevention and Con- trol, Collaborative Innovation Center for Diagnosis and Treatment of Infectious Diseases, National Institute for Communicable Disease Control and Prevention, Chinese Center for Disease Control and Prevention (China CDC), P.O. Box5, Changping District, Beijing 102206, People's Republic of China.}

\section{Acknowledgements}

We thank the staff of Departamento Académico de Ciencias Básicas, Universidad Nacional Amazónica de Madre de Dios.

\section{Competing interests}

On behalf of all authors, the corresponding author states that there are no Competing interests or funding related to this study.

\section{Availability of data and materials}

Abstraction format used in the study and dataset are available and accessible from the corresponding author upon request in the link: https://figshare.com/ articles/Dataset_ticks_2018/5774088.

\section{Consent to publish}

Not applicable.

\section{Ethics approval and consent to participate}

This study was approved by the National Committee of Health and Environment from the Regional Government of Madre de Dios and the Institutional 
Animal Care and Use Committee (IACUC) from the U.S. Naval Medical Research Unit No. 6 (NAMRU-6) memorandum 072102.

\section{Funding}

This work was supported by the Programa Nacional de Innovación para la Competitividad y Productividad (Innóvate Perú)-contract 117-PNICP-PIAP-2015.

This work was supported by Cienciativa of CONCYTEC Peru, under the contract N ${ }^{\circ} 164-2016-F O N D E C Y T$. Dr. Lescano is sponsored by the training grant D43 TW007393 awared by the Fogarty International Center of the US National Institutes of Health.

\section{Publisher's Note}

Springer Nature remains neutral with regard to jurisdictional claims in published maps and institutional affiliations.

Received: 12 April 2018 Accepted: 19 June 2018

Published online: 25 June 2018

\section{References}

1. Huarcaya E, Maguiña C, Torres R, Rupay J, Fuentes L. Bartonelosis (Carrion's Disease) in the pediatric population of Peru: an overview and update. Braz J Infect Dis. 2004;8(5):331-9.

2. Chomel BB, Kasten RW. Bartonellosis, an increasingly recognized zoonosis. J Appl Microbiol. 2010;109(3):743-50.

3. Diniz PP, Morton BA, Tngrian M, Kachani M, Barrón EA, Gavidia CM, et al. Infection of domestic dogs in Peru by zoonotic Bartonella species: a cross-sectional prevalence study of 219 asymptomatic dogs. PLoS Negl Trop Dis. 2013;7(9):e2393.

4. Silaghi C, Pfeffer M, Kiefer D, Kiefer M, Obiegala A. Bartonella, rodents, fleas, and ticks: a molecular field study on host-vector-pathogen associations in Saxony, Eastern Germany. Microb Ecol. 2016;72(4):965-74.

5. Minnick MF, Battisti JM. Pestilence, persistence, and pathogenicity: infection strategies of Bartonella. Fut Microbiol. 2009;4(6):743-58.

6. Schülein R, Seubert A, Gille C, Lanz C, Hansmann Y, Piémont Y, et al. Invasion and persistent intracellular colonization of erythrocytes. A unique parasitic strategy of the emerging pathogen Bartonella. J Exp Med. 2001;193(9):1077-86.

7. Minnick MF, Anderson BE, Lima A, Battisti JM, Lawyer PG, Birtles RJ. Oroya fever and verruga peruana: bartonelloses unique to South America. PLoS Negl Trop Dis. 2014;8(7):e2919.

8. Eremeeva ME, Gerns HL, Lydy SL, Goo JS, Ryan ET, Mathew SS, et al. Bacteremia, fever, and splenomegaly caused by a newly recognized Bartonella species. N Engl J Med. 2007;356:2381-7.

9. Maguiña C, Ugarte-Gil C, Breña P, Ordaya E, Ventosilla P, Huarcaya E, et al. Update of Carrion's disease. Rev Med Hered. 2008;19(1):36-41.

10. Blazes DL, Mullins K, Smoak BL, Jiang J, Canal E, Solorzano N, et al. Novel Bartonella agent as cause of verruga peruana. Emerg Infect Dis. 2013;19(7):1111-4.

11. Mendoza-Mujica G, Flores-León D. Antimicrobial resistance of Bartonella bacilliformis strains from regions endemic to Bartonellosis in Peru. Rev Peru Med Exp Salud Publica. 2015;32(4):659-66.

12. Jacomo V, Kelly PJ, Raoult D. Natural history of Bartonella infections (an exception to Koch's postulate). Clin Diagn Lab Immunol. 2002;9:8-18.

13. Maguina C, Garcia PJ, Gotuzzo E, Cordero L, Spach DH. Bartonellosis (Carrion's disease) in the modern era. Clin Infect Dis. 2001;33(6):772-9.

14. Silva-Caso W, Pons M, Ruiz J, del Valle-Mendoza J. Antibiotic resistance in Bartonella bacilliformis clinical isolates from an endemic area of Peru. J Glob Antimicrob Resist. 2015:3(3):222-3.

15. Acosta O, Solano L, Escobar J, Fernandez M, Solano C, Fujita R. Frequencies of blood group systems MNS, Diego, and duffy and clinical phases of Carrion's disease in Amazonas, Peru. Interdiscip Perspect Infect Dis. 2014:2014:1-8.

16. Caceres AG. Geographic distribution of Lutzomyia verrucarum (Townsend, 1913) (Diptera, Psychodidae, Phlebotominae), vector of human bartonellosis in Peru. Rev Inst Med Trop Sao Paulo. 1993;35(6):485-90.
17. Caceres AG, Galati EA, Le Pont F, Velasquez C. Possible role of Lutzomyia maranonensis and Lutzomyia robusta (Diptera: Psychodidae) as vectors of human bartonellosis in three provinces of region nor Oriental del Marañon, Peru. Rev Inst Med Trop Sao Paulo. 1997;39(1):51-2.

18. Chamberlin J, Laughlin L, Romero S, Solorzano N, Gordon S, Andre R, et al. Epidemiology of endemic Bartonella bacilliformis: a prospective cohort study in a Peruvian mountain valley community. J Infect Dis. 2002;186(7):983-90.

19. Gomes C, Pons MJ, Del Valle Mendoza J, Ruiz J. Carrion's disease: an eradicable illness? Infect Dis Poverty. 2016;5(1):105-9.

20. Breitschwerdt EB. Bartonellosis, one health and all creatures great and small. Vet Dermatol. 2017;28(1):96-e21.

21. Ereqat S, Nasereddin A, Vayssier-Taussat M, Abdelkader A, Al-Jawabreh A, Zaid T, et al. Molecular evidence of bartonella species in ixodid ticks and domestic animals in Palestine. Front Microbiol. 2016;7:1217.

22. Davoust B, Marié JL, Dahmani M, Berenger JM, Bompar JM, Blanchet $D$, et al. Evidence of Bartonella spp. in blood and ticks (Ornithodoros hasei) of bats, in French Guiana. Vector Borne Zoonotic Dis. 2016:16(8):516-9.

23. Malheiros J, Costa MM, do Amaral RB, de Sousa KC, André MR, Machado $R Z$, et al. Identification of vector-borne pathogens in dogs and cats from Southern Brazil. Ticks Tick Borne Dis. 2016;7(5):893-900.

24. Carrapatos de Importância Médico-Veterinária da Região Neotropical: Um guia ilustrado para identificação de espécies; por Darci Moraes Barros-Battesti, Márcia Arzua e Gervásio Henrique Bechara. São Paulo, Vox/ICTTD-3/Butantan, 2006.

25. Li DM, Liu YY, Du PC, Song XP, Liu QY. Detection of Bartonella bacilliformis by real-time PCR with TaqMan-MGB probe. Microbiol China. 2015;42(2):427-35.

26. Alexander B. A review of Bartonellosis in Ecuador and Colombia. Am J Trop Med Hyg. 1995;52(4):354-9.

27. Laval R. Daniel alcides Carrion. Rev Chil Infectol. 2003:20:36.

28. Pons MJ, Gomes C, Del Valle-Mendoza J, Ruiz J. Carrion's disease: more than a sand fly-vectored illness. PLoS Pathog. 2016;12(10):e1005863.

29. Hijar G, Bonilla C, Munayco C, Gutierrez E, Ramos W. El niño phenomenon and natural disasters: public health interventions for disaster preparedness and response. Rev Peru Med Exp Salud Publica. 2016;33(2):300-10.

30. Anaya E, Cespedes M, Mostorino R. Bartonellosis en Madre de Dios. Lima, Boletín INS; 2004. cited on 10 April 2017. http://repositorio.ins.gob.pe/ handle/INS/802. Accessed 22 Mar 2017.

31. Del Valle Mendoza J, Silva Caso W, Tinco Valdez C, Pons MJ, Del Valle LJ, Ore VC, et al. Diagnosis of Carrion's disease by direct blood PCR in thin blood smear negative samples. PLoS ONE. 2014;9(3):e92283.

32. Valdivia H, De Los Santos M, Fernandez R, Baldeviano G, Zorrilla V, Vera $H$, et al. Natural leishmania infection of Lutzomyia auraensis in Madre de Dios, Peru, detected by a fluorescence resonance energy transferbased real-time polymerase chain reaction. Am J Trop Med Hyg. 2012:87(3):511-7.

33. Labruna M, Romero M, Martins T, Tobler M, Ferreira F. Ticks of the genus amblyomma (Acari: Ixodidae) infesting tapirs (Tapirus terrestris) and peccaries (Tayassu pecari) in Peru. Syst Appl Acarol. 2010;15(2):109-12.

34. Persichetti MF, Solano-Gallego L, Serrano L, Altet L, Reale S, Masucci M, et al. Detection of vector-borne pathogens in cats and their ectoparasites in southern Italy. Parasit Vectors. 2016:9(1):247-54.

35. Lockwood S, Brayton KA, Broschat SL. Comparative genomics reveals multiple pathways to mutualism for tick-borne pathogens. BMC Genom. 2016;17(1):481-91.

36. McKee CD, Hayman DT, Kosoy MY, Webb CT. Phylogenetic and geographic patterns of Bartonella host shifts among bat species. Infect Genet Evol. 2016:44:382-94

37. Alsmark CM, Frank AC, Karlberg EO, Legault BA, Ardell DH, Canbäck B, et al. The louse-borne human pathogen Bartonella Quintana is a genomic derivative of the zoonotic agent Bartonella henselae. Proc Natl Acad Sci USA. 2004;101(26):9716-21.

38. Sanchez Clemente N, Ugarte-Gil CA, Solórzano N, Maguiña C, Pachas P Blazes D, et al. Bartonella bacilliformis: a systematic review of the literature to guide the research agenda for elimination. PLoS Negl Trop Dis. 2012;6(10):e1819.

39. Ogusuku E, Perez J, Paz L, Nieto E, Monje J, Guerra H. Identification of bloodmeal sources of Lutzomyia spp. Peru. Ann Trop Med Parasitol. 1994:88(3):329-35. 